Г.В. Китайгородская, Е.В. Поляков

Сыктывкар

\title{
МУЗЕЙ УЧИТЕЛЬСТВА РЕСПУБЛИКИ КОМИ КАК ГУМАНИТАРНЫЙ ПРОЕКТ В СИСТЕМЕ СОВРЕМЕННОГО ОБРАЗОВАНИЯ РЕГИОНА
}

Цитирование: Китайгородская Г.В., Поляков Е.В. Музей учительства Республики Коми как гуманитарный проект в системе современного образования региона // Наследие. 2020, № 2(17). - С.196-203.

DOI: https://doi.org/10.31119/hrtg.2020.2.13

Citation: Kitaygorodskaya G.V., Polyakov E.V. Muzej uchitel'stva Respubliki Komi kak gumanitarnyj proekt $v$ sisteme sovremennogo obrazovaniya regiona [Museum of teachers in the Komi Republic as a humanitarian project in the modern education system of the region] // Nasledie [Heritage]. 2020, No. 2 (17). - pp.196-203.

DOI: https://doi.org/10.31119/hrtg.2020.2.13

В статье рассмотрена конщепщия создания Музея учительства Республики Коми с ичелью сохранения профессиональных педагогических традииий, транслящии исторической памяти о передовых учителях Республики Коми. Особое внимание уделено раскрытию особенностей музейного проектирования и роли Музея учительства как научно-образовательного и социокультурного проекma.

Ключевые слова: музей, учительство, образование, педагогические традиции, проектирование.

Kitaygorodskaya G.V., Polyakov E.V. Museum of teachers in the Komi Republic as a humanitarian project in the modern education system of the region

The article deals with the concept of creating the Museum of teachers in the Komi Republic, which aims to preserve professional pedagogical traditions, broadcast the historical memory of the leading teachers of the Komi Republic. Special attention is paid to the disclosure of the features of the Museum design and the role of the Museum as a scientific, educational and socio-cultural project.

Key words: museum, teachers, education, pedagogical traditions, project.

«Учителя в своей совокупности влияют на ход истории своего народа не меньше, а больше, чем глава государства или глава церкви...Это следует помнить всякому народу, желающему жить и процветать» [Сорокин, 2019]. Такую высокую оценку деятельности учителя дал в своих научных трудах выдающийся ученый-социолог и общественный деятель П.А. Сорокин. 
На всем протяжении истории отечественной школы наиболее важной фигурой в системе образования и ее неотъемлемой составляющей являлся и является школьный учитель. Однако в 1990-е гг. прошлого столетия в стране произошли крупные социально-политические изменения, связанные с трансформацией общественного сознания. В российском обществе стал ощущаться недостаток сознательно принимаемых большинством граждан принципов и правил жизни, на его жизнь негативно влияло отсутствие согласия в вопросах корректного и конструктивного социального поведения. Эти явления оказывали отрицательное влияние на общественную нравственность, гражданское самосознание, отношение людей к обществу, государству, закону и труду, на отношение человека к человеку. Трансформация общественного сознания привела к изменению отношения к педагогической профессии и, как следствие, - социального статуса учителя в результате падения привлекательности профессии педагога.

Одна из важнейших общесистемных функций современной системы образования - ресурсная, под которой понимается формирование и развитие личностного профессионального капитала педагога. Ключевые мероприятия системы направлены не только на поддержку профессионального развития каждого педагога, но и на формирование механизмов государственной поддержки профессиональных инициатив, признание ценности труда педагогов как активных трансляторов государственной политики в процессе воспитания граждан России. В этой связи особое звучание приобретает одна из целей национального проекта «Образование»: «воспитание гармонично развитой и социально ответственной личности на основе духовно-нравственных ценностей народов Российской Федерации, исторических и национально-культурных традиций» [Национальный проект...].

Функционирование национальной системы профессионального роста педагогических работников сегодня рассматривается как главный интегратор педагогической жизни страны, обусловливающий укрепление единого образовательного и профессионального пространства России. В этом смысле непрерывное педагогическое образование необходимо рассматривать как канал вертикальной циркуляции, позволяющий педагогу в дальнейшем не только иметь более высокий социальный и государственный статус [Сорокин, 1992, с.146], но и участвовать в принятии значимых решений на уровне региона, на уровне региональных и трансграничных систем образования. Актуальная задача сегодня - привлечь внимание молодых креативных выпускников общеобразовательных организаций, выпускников организаций среднего профессионального и высшего образования не только педагогических направлений, но и непедагогических к учительской профессии: пройдя психологопедагогическую подготовку, освоив новые образовательные технологии, они смогут дать импульс к обновлению и развитию предметных систем.

Региональная образовательная модель должна пониматься как основная социально-культурная платформа для позиционирования роли учителя в динамичном обновлении общества. Эта платформа должна интегрировать государственные и социальные цели, образовательные ресурсы и личностные перспективы.

Проект, реализованный командой ГОУДПО «Коми республиканский институт развития образования», является профессиональным пространством для представления интеллектуальных практик развития региональной системы учительства. 
28 февраля 2019 г. в Коми республиканском институте развития образования был открыт музей учительства Республики Коми. Его главной целью является формирование личного эмоционального отношения к педагогической профессии, позиционирование высокого авторитета педагога, осознание важности учительства как социокультурного феномена современного общества. Музей обеспечивает исследование истории учительства в Коми крае в его преемственности, позволяет проследить процессы его модернизации и способствует сохранению профессиональных традиций.

Термин «учительство» широко применялся в дореволюционный и советский период истории нашей страны. Педагогические журналы конца XIX - начала XX в. использовали для выделения учительской группы такие термины, как «учащее сословие» или «учительское сословие», «учащие лица», «класс учителей», «лица педагогического мира», «учительская братия». Слово «учительство» объединяло все вышеперечисленные термины и представляло собой открытую профессиональную группу, управляемую государством, члены которой находятся в непосредственном образовательном контакте с учащимися. Кроме этого, под словом «учительство» понималась и непосредственная профессиональная деятельность учителей [Ефремова, 2000].

Проект создания Музея учительства Республики Коми состоит из нескольких этапов. Первый - подготовительный - этап включал в себя разработку концепции будущего музея, которая была осуществлена Г.В. Китайгородской, В.А. Сулимовым. Главная идея, обозначенная в концепции, состояла в том, что Музей учительства должен представлять собой собрание документов и фотографий, посвященных становлению и развитию учительского труда в Республике Коми в период с 1864 - по настоящее время, а также предметов и оснащения школ разного периода, личных

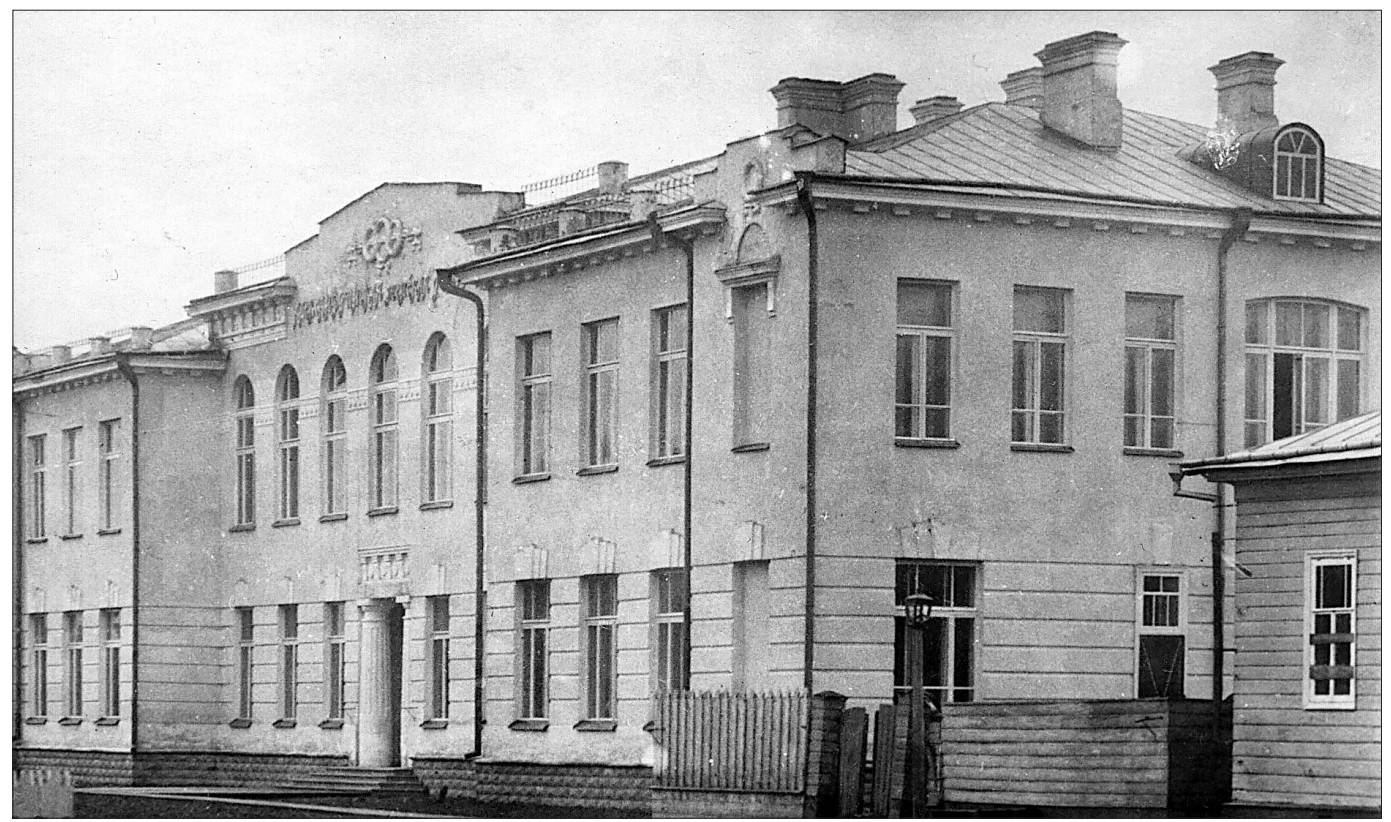

Александринская женская гимназия. Нач. ХХ в. г. Усть-Сысольск, ул. Покровская 
вещей выдающихся учителей республики, руководителей системы образования. Формы презентации экспонатов: материальная, виртуальная (компьютерная), визуально-художественная (фильмы). В концепции была отражена особенность экспозиционного пространства музея - он должен располагаться в одной аудитории и содержательно разделен на следующие экспозиционные зоны: «Заслуженные учителя Республики Коми», «Учительство в Коми крае в дореволюционный период (1864 1918)», «Советский учитель - воспитатель и наставник (1918-1941)», «Коми школа в годы Великой Отечественной войны (1941-1945)», «Советская школа: к новым рубежам социализма (1945-1991)», «Российский учитель в трудах и победах (1992настоящее время)».

Следующим этапом реализации проекта «Музей учительства Республики Коми» стала непосредственно работа над созданием будущего музея, которая предусматривала учет принципов научности, предметности, доступности и открытости музейных экспозиций.

Принцип научности выражается в научном освещении вопросов, связанных с историей учительства Республики Коми, и их отражении в текстах для экспозиций музея и этикетажа. В ходе подготовки экспозиций музея изучались труды авторитетных ученых-историков Республики Коми, занимающихся проблемой истории народного образования в Коми крае: О.Е. Бондаренко [Бондаренко, 1998], П.В. Габова [Габов, 2006], И.Л. Жеребцова [Жеребцов, 2005], О.В. Золотарева [Золотарев, 2015] и др.

Проектирование Музея учительства Республики Коми осуществлялось также с учетом принципа предметности. По мнению выдающегося ученого-музееведа Б.А. Столярова, «музейный предмет (экспонат) - это основа уникальности каждой

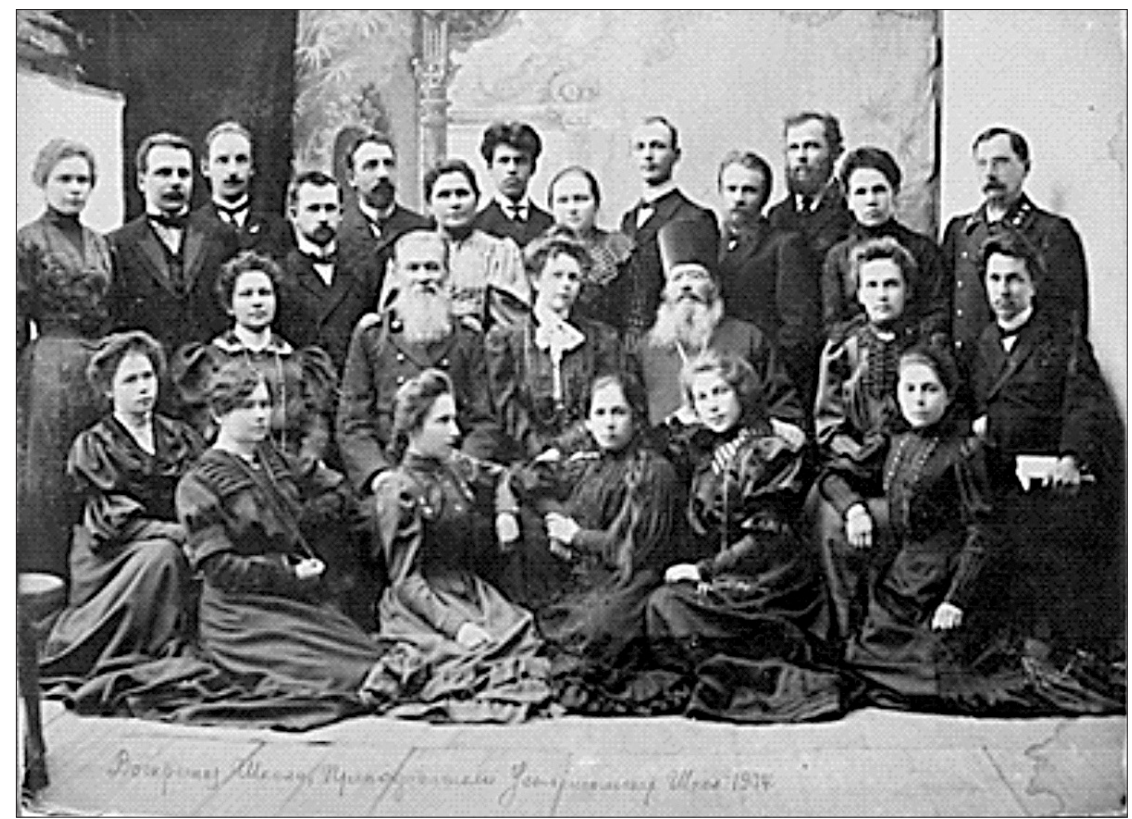

Преподаватели Воскресной школы, учителя всех усть-сысольских школ. 1904 г. 
экспозиции» [Столяров, 2004, с.20]. Именно от правильного подбора и размещения музейных предметов зависит познавательная (когнитивная) ценность будущей экспозиции и ее эмоциональная направленность. В Музее учительства Республики Коми представлены следующие виды экспонатов: документы (свидетельства об окончании учебных заведений, табели успеваемости, дипломы, дневники, грамоты и др.), фотографии (фотоснимки педагогов, мастер-классов, образовательных учреждений и др.), средства обучения (учебные пособия, методические пособия, ученические тетради, и др.), учебное оборудование (арифмометр, школьные счеты, диапроектор, диафильмы, диапозитивы, записи на грампластинках и ленте и др.), школьные и учительские знаковые атрибуты (наградные значки, школьная форма, пионерский галстук и др.).

В Музее учительства можно увидеть фотографии из фондов Национального музея Республики Коми, которые ранее не публиковались и не демонстрировались на экспозициях. Особо ценными являются следующие фотоснимки дореволюционного периода: «Преподаватели и ученицы Усть-Сысольской женской прогимназии» (1910-е гг.), «Выпускники Вильгортского земского начального училища с учительницей Забоевой Феоктистой Ивановной» (1910), «Преподаватели Усть-Сысольской женской и мужской гимназий» (1908-1909), «Преподаватели Воскресной школы, учителя всех усть-сысольских школ» (1904), «Кашина Апполинария Варламовна первая учительница поселка Нювчим церковно-приходской школы» (1913), «Учителя двухклассного приходского училища в селе Усть-Цильма» (1910), «Чеусова Анна Николаевна - учительница в земских училищах Усть-Сысольского уезда» (1915), «Фролов Александр Георгиевич, учитель, краевед, уроженец г. Усть-Сысольска, участник І мировой войны» (1917), «Гимназисты и преподаватели Усть-Сысольской мужской гимназии в кабинете физики» (1910).

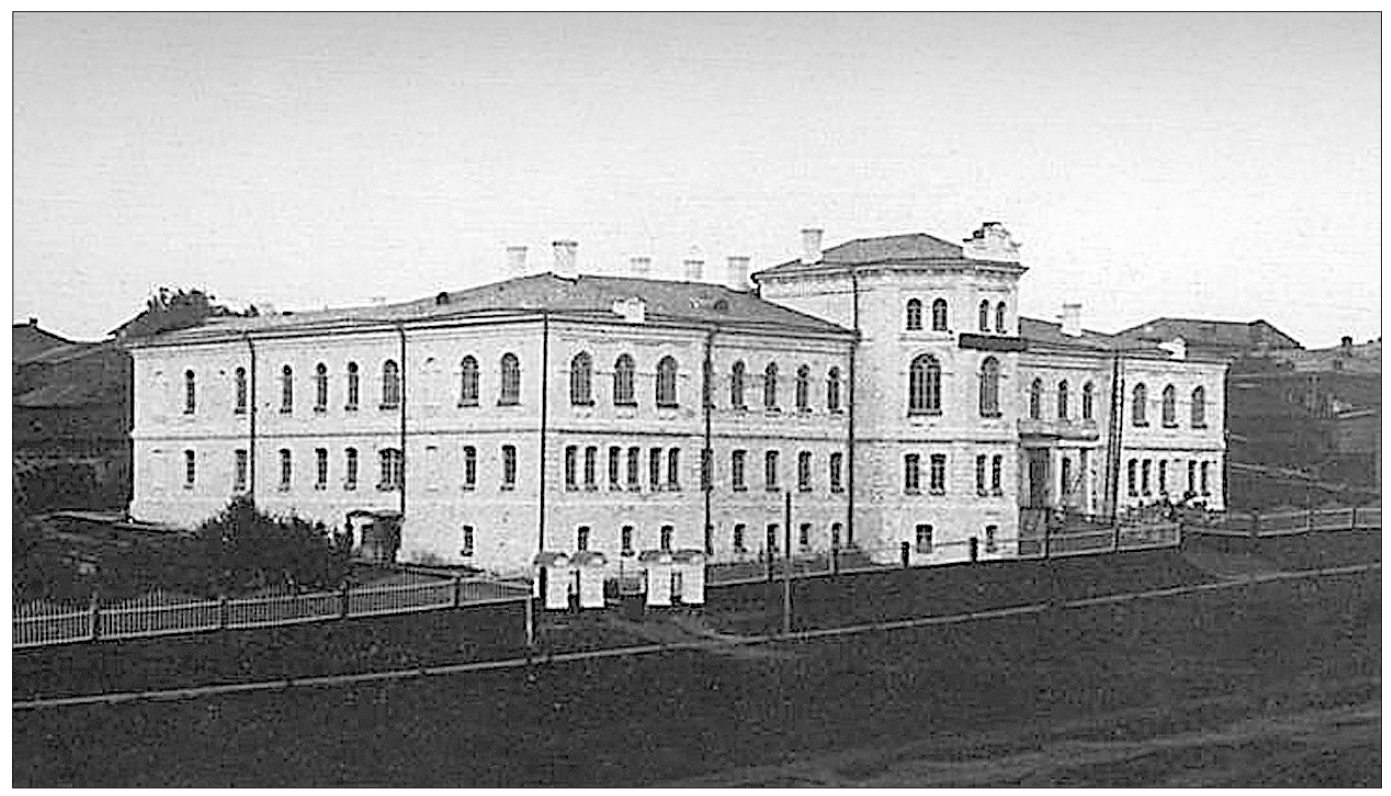

Усть-Сысольское духовное училище. Нач. XX в. 
Концепция предполагает наличие в музейной среде как материальных, так и виртуальных экспонатов. Ведущими программистами Коми республиканского института развития образования А.М. Дроновым и А.С. Дроновой по технологии 3D моделирования «Дополненная реальность» были созданы два альбома виртуальных экспонатов: «Ретроспектива истории школы в Коми крае (1864-1917)» и «Ретроспектива истории школы в Коми ACCР». В данных альбомах размещены QR-коды, в которых «зашифрованы» предметы школьного обихода разных лет. С помощью планшета или смартфона посетитель музея может внимательно рассмотреть интерактивный закодированный экспонат в трехмерном изображении.

Проектирование Музея учительства было направлено на реализацию принципа доступности и открытости музейных экспозиций. Классический, традиционный музей предполагает «закрытость» музейных экспонатов: часто в музеях можно увидеть табличку «Трогать руками запрещено!». В Музее учительства Республики Коми, напротив, часть экспонатов можно изучить как зрительно, так и тактильно. Например, детально изучить принцип работы школьного арифмометра или попробовать посчитать, используя школьные счеты.

Доступность Музея учительства также обеспечивает аудиогид. Рядом с каждой экспозицией размещен QR-код, а также электронная ссылка на аудиотекст. Таким образом, можно совершить экскурсию по музею самостоятельно, без экскурсовода.

Музей учительства Республики Коми можно назвать инновационным, поскольку в нем представлена виртуальная экспозиция. Виртуальный музей включает в себя следующие воссозданные интерьеры классных комнат различных образовательных учреждений Коми края: «Церковно-приходская школа в Коми крае (1864-1918)», «Земская школа в Коми крае (1864-1918)», «Александринская женская гимназия в г. Усть-Сысольске (1864-1918)», «Советская школа (1918-1941)», «Советская шко-

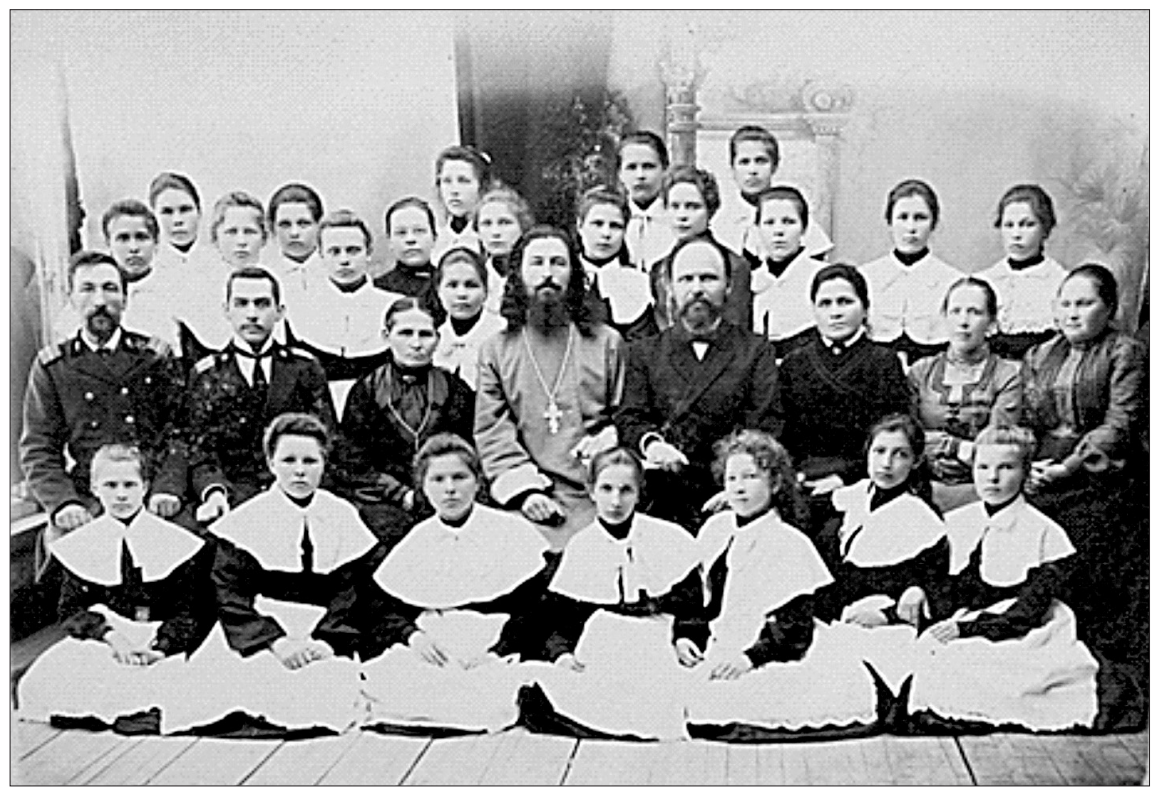

Преподаватели и ученицы Усть-Сысольской женской прогимназии. 1910-е гг. 
ла в годы Великой Отечественной Войны (1941-1945)», «Советская школа (19451991)», «Современная российская школа: модернизация современного образования (1992 - настоящее время)».

Функциями виртуального музея является знаково-символическое воссоздание определенных периодов истории образования в Коми крае в конце XIX-XX в. Историческая реконструкция позволит «перенестись» в прошлое, рассмотреть преемственность развития образования. Современные технологии делают возможным доступ к коллекциям посредством сети Интернет [Селиванов, 1992, с.199]. Виртуальный музей станет площадкой коммуникативного взаимодействия посетителя с интерактивной экспозицией по принципу «диалога», музейной коммуникации.

Третий - заключительный - этап реализации проекта «Музей учительства Республики Коми» - это функционирование самого музея. В планах работы музея систематическая деятельность по дальнейшему комплектованию основного и вспомогательного фондов, организация временных выставок, проведение тематических музейных мероприятий и конкурсов.

В Музее учительства планируется организовывать ежегодные выставки, посвящённые знаменитым учителям Республики Коми. Так, 2020 г. была организована временная выставка «Учителя-фронтовики», посвященная 75-летию Победы в Великой Отечественной войне. Посетители тематической выставки узнали краткую фронтовую историю следующих педагогов Коми АССР: А.В. Уляшева, Д.Г. Напалкова, С.Л. Куликова, Н.А. Исакова, Н.Ф. Некрасова, Д.Я. Кутьина, С.И. Майбурова, В.И. Шешукова, С.Д. Некрасова, П.И. Нехорошева, П.Я. Оботурова, А.А. Плоскова, М.М. Макарова, П.С. Ларева, В.А. Шергина, К.Н. Туркина.

В 2020 г. в рамках научно-исследовательской работы музея стартовал республиканский конкурс творческих проектов «Учительская династия», в котором приняли участие 27 педагогов - представителей многопоколенных учительских династий Республики Коми. Таким образом, можно говорить о том, что Музей учительства представляет собой не только культурно-просветительский, но и социокультурный центр, который объединяет разные педагогические сообщества: молодых педагогов, учителей-методистов, ветеранов учительского движения, управленцев системы образования.

Современный Музей учительства Республики Коми является ярким примером взаимодействия старых и новых музейных технологий - технологий классического музееведения и интерактивных визуальных пространств, которые действуют по принципу взаимодополнения. Музей учительства как гуманитарный проект в системе современного образования региона способен стать центром объединения разных педагогических сообществ, способен формировать личное эмоциональное отношение к педагогической профессии и позиционировать высокий авторитет учителя.

\section{Литература}

Бондаренко O.E. Учебные заведения в Коми крае в конце XIX - начале XX веков. Сыктывкар, 1998. $190 \mathrm{c}$.

Габов П.В. Развитие национальной школы в конце XX века: исторические аспекты и современное состояние изучения в ней родного языка (на примере Республики Коми) / П.В. Габов // Финно-угроведение. Йошкар-Ола: МарНИИЯЛИ. 2006, № 1. - С.100-107. 
Ефремова Т.Ф. Новый словарь русского языка. Толково-образовательный. М.: Рус. яз., 2000 , в 2 т. $1209 \mathrm{c}$.

Жеребцов И.Л. Стоявшие у истоков (Очерки истории становления гуманитарной науки в Коми). Сыктывкар: РИО ИЯЛИ Коми НЦ УрО РАН, 2005. - 108 с.

Золотарев О.В. Коми учительство: краткий очерк истории / О.В. Золотарев; науч. ред. Д.и.н. И.Л. Жеребцов; Федер. агентство науч. организаций, Институт языка, литературы и истории Коми НЦ УрО РАН. Научное издание. Сыктывкар: ИЯЛИ Коми НЦ УрО РАН, 2015. - 183 с.

Национальный проект «Образование»// Министерство просвещения Российской Федерации [http:// edu.gov.ru/national-project/]

Селиванов Н.Л. Субъективный взгляд на музей из виртуальной реальности // Музей и новые технологии: на пути к музею XXI века / сост. и научн. ред. Н.А. Никишин. М.: Прогресс-Традиция, 1992. - С.198-204.

Сорокин П.А. Человек. Цивилизация. Общество / Общ. ред., сост. и предисл. А. Ю. Согомонов: Пер. с англ. М.: Политиздат, 1992. - 543 с.

Сорокин П.А. Популярные очерки теории права, социологии и социальной педагогики / Сост., подгот. текста, вступ. ст. и коммент. В.В. Сапова. Сыктывкар: ООО «Анбур», 2019. - 470 с.

Столяров Б.А. Музейная педагогика. М., 2004. - 216 с.

\section{References}

Bondarenko O.E. Uchebnye zavedeniya v Komi krae v konce XIX-nachale XX vekov [Educational institutions in the Komi region in the late XIX - early XX centuries]. Syktyvkar, 1998. - 190 p.

Gabov P.V. Razvitie nacional'noj shkoly v konce XX veka: istoricheskie aspekty i sovremennoe sostoyanie izucheniya $v$ nej rodnogo yazyka (na primere Respubliki Komi) [The development of the national school at the end of the XX century: historical aspects and the current state of learning the native language in it (on the example of the Komi Republic)] / P. V. Gabov // Finno-Ugric studies. - Yoshkar-Ola: Marniiyali, 2006. - N. 1. - P.100-107.

Efremova T.F. Novyj slovar' russkogo yazyka. Tolkovo-obrazovatel'nyj [The new dictionary of the Russian language. Sensible- educational]. - M.: Rus. yaz. 2000. - in 2 vols. - 1209 p.

Zherebtsov I.L. Stoyavshie u istokov (Ocherki istorii stanovleniya gumanitarnoj nauki v Komi) [Standing at the origins (Essays on the history of the formation of Humanities in Komi)]. Syktyvkar: RIO ILLH Komi SC UB RAS, 2005. - 108 p.

Zolotarev O.V. Komi uchitel'stvo: kratkij ocherk istorii [Komi teachers: a brief outline of history] / O.V. Zolotarev; scientific ed., Doctor of Science (History) I. L. Zherebtsov; Feder. Agency of scientific organizations, Institute of language, literature and history of the Komi science center of the Ural Branch of the Russian Academy of Sciences - Scientific publication. Syktyvkar: RIO ILLH Komi SC UB RAS, 2015. $-183 \mathrm{p}$.

Sorokin P.A. Populyarnye ocherki teorii prava, sociologii i social'noj pedagogiki [Popular essays on the theory of law, sociology and social pedagogy] / Comp., prep. text, introductory article and commentary by V. V. Sapov. - Syktyvkar: «Anbur», $2019-470$ p.

Stolyarov B.A. Muzejnaya pedagogika [Museum pedagogy]. M., 2004. - 216 p.

Sorokin P.A. Human. Civilization. Society [Chelovek. Civilizaciya. Obshchestvo] / General ed., comp. and preface by A. Y. Sogomonov: trans1/ from Engl. M.: Politizdat, 1992. - 543 p.

Selivanov N.L. Sub'ektivnyj vzglyad na muzej iz virtual'noj real'nosti [The subjective view of the Museum from a virtual reality] // Museum and new technologies: on the way to the Museum of the XXI century / comp. and scientific. ed. N. A. Nikishin, M.: Progress-Tradition, 1992. - P.198-204. 